\title{
WORD ORDER AND FOCUSING EFFECTS IN THE MEMORY REPRESENTATION OF HUNGARIAN SENTENCES*
}

\author{
CSABA PLÉH ${ }^{\mathrm{a}}$ - BALÁZS SINKOVICS ${ }^{\mathrm{b}}$ \\ ${ }^{a}$ Department of Cognitive Science, Budapest University of Technology \\ and Economics, Hungary \\ ${ }^{\mathrm{b}}$ Department of Hungarian, University of Szeged, Hungary \\ Corresponding author: Csaba Pléh, address: Stoczek u. 2., H-1111 Budapest, \\ Hungary, e-mail: pleh@cogsci.bme.hu
}

\begin{abstract}
In two acoustic sentence recognition experiments the relative importance of recognition times ( 0 to 40 seconds) and relationships between the target sentence and test sentences were varied. Hungarian promised to be a good testing ground for traditional theories that claim that while form is readily forgotten, sentence meaning is preserved. In Hungarian, the informational structure of sentences allows for clear contrasts between neutral and meaning-related order variations. In the stimulus material, target sentences were compared in recognition scores with identical, neutral word order, paraphrased, and focused sentence pairs. The results partly support our starting hypotheses, but partly show that the intricacies of Hungarian sentential syntax call for a more reserved and more carefully qualified expression of the initial proposals of Sachs (1967) and Johnson-Laird and Stevenson (1970). Focused sentences are clearly contrasted with non-focused initial targets even after 40 seconds. It seems that the information structure of Hungarian sentences is somehow maintained in the long-term memory system. In accordance with the classical results, meaning-neutral word order variations are misrecognized in about 60 per cent after 16 seconds already. Contrary to our hypothesis, even after 40 seconds, paraphrases were correctly recognized more than 60 per cent of the time. Thus, to clarify memorial paraphrase equivalence to cross-linguistic validity, more types of sentential paraphrases should be compared. The study supports the main ideas underlying the experiments: the informational structure of the Hungarian sentence seems to be retained in long-term memory, unlike neutral word order variations. This finding calls for a more detailed study with more varied stimulus materials to clarify some further issues of what is 'form' and what is 'meaning' for the memory system.
\end{abstract}

Keywords: Hungarian sentence structure, focusing, sentence memory, memory for meaning, word order and memory, paraphrase in memory

* Detailed comments on an earlier version of the manuscript by Ágnes Lukács and Ferenc Kemény helped us to clarify our arguments. 


\section{Introduction}

The issue of retaining content and forgetting the form of sentences is a classical observation of experimental psycholinguistics. Following a decade of mainly off-line research for the memory for syntactic form versus "gist", summarized by Fillenbaum (1973) and Flores d'Arcais (1974), more on-line studies initiated by Sachs (1967) showed that in an acoustic recognition task people tend to ignore active-passive differences already after a delay of 40 syllables (12 seconds) while they notice Agent changes even after 80 interposed syllables ( 25 seconds). JohnsonLaird and Stevenson (1970) showed that the representation retained over longer periods must be even more abstract since after 50 seconds, differences between The painter sold the painting to the businessman and The painting was bought by the businessman from the painter are neutralized in the memory representation.

These classic effects were obtained at a time where semantic or meaning-related representation was contrasted to syntax-based theories of sentence memory. However, as the memory representation literature started to concentrate more and more on general meaning-based theories of linguistic memory such as Kintsch (1974), the original alliance between ideas regarding sentence processing and memory representation were lost (Kintsch et al. 1990). In the model proposed by Anderson et al. (2001), the memory traces for parsing and ties to referents (pointers in their terminology), as well as to long-term memory representations of facts, are assumed to be stored in a common format. In models of this type the idea of specific representation of meaning or gist is openly questioned. While the observations on the importance of meaning being preserved better than any aspect of syntactic roles have become standard textbook material since Clark-Clark (1977), there was practically no continuation, from the 1980s on, of the original approach contrasting aspects of syntaxvs. meaning-based memory representation.

The present paper has two aims: first, to revive this interest towards fast forgetting of form and relatively stable memory for meaning in linguistic materials; second, and more importantly, to combine this with some particularities of Hungarian syntax. An attempt was made to test whether the peculiarities of the information structure of the Hungarian sentence challenge the traditional idea claiming that word order is soon forgotten. In the traditional literature referred to above, word order was used as a trivial aspect of form that is easily forgotten. However, there 
are languages such as Hungarian that have an information structure that is challenging to the idea that equates weak memory for form with forgetting word order. Basically, in Hungarian sentence structure, "free word order" with respect to propositional structure and argument roles on the level of the ordering of major constituents is combined with a clear and formalized role of word order in carrying discourse-related information such as focusing. As Kiefer (2005) pointed out, following Lambrecht (1994), information structure in Hungarian is the formalized expression of pragmatic distinctions.

In this model of Hungarian sentence structure (É. Kiss 1981a;b; 1987), basically the immediately preverbal position carries the (contrastive) focus information. Thus the neutral sentence (1) has several different discourse-related articulations as in (2)-(4). Prefixed verbs are used in the examples, since on the marking level, focusing is indicated both by removing the preverbal modifiers from the focus slot, and by emphasis (an elevated accent) that is indicated by "in the examples.

(1) A katona megcsókolta a rendőrt.

the soldier pref-kissed the cop-acc

'The soldier kissed the cop.'

(2) Subject focus: A "katona csókolta meg a rendőrt.

'The SOLDIER kissed the cop.'

(3) Object focus: A katona a "rendőrt csókolta meg.

'The soldier kissed the COP.'

(4) Verb focus: A katona a rendőrt "megcsókolta.

'The soldier KISSED the cop.'

In earlier elicited recall studies of Hungarian sentences by preschool children it was observed that the immediately preverbal position has indeed a privileged place in short-term recall. When children were asked to repeat structures like (3), they frequently omitted extraneous materials such as adjectives and adverbs, and had a tendency to move the preverbal modifier to the preverbal slot, thus changing (3) to (1) (Pléh et al. 1989).

In the present study, two experiments were performed to look for an adaptive storage of word order information in adult recognition memory for Hungarian sentences after various delays. Four hypotheses were tested: 
Hypothesis 1: Word order changes relevant to information structure are retained. Meaning-relevant (i.e., Focus-related) order changes are treated by the processing system similarly to propositional thematic order changes. Changes in information structure are recognized even after several dozen seconds, the same way as changes in thematic role assignments are. Thus, information structure in Hungarian is treated by the memory system similarly to propositional structure.

Hypothesis 2: Forgetting of form. Meaning-neutral order variations tend to be forgotten already after short delays.

Hypothesis 3: Meaning equivalence of paraphrases in memory. Meaning preserving/synonymous variations are not recognized as changes.

Hypothesis 4: Fast forgetting of form, slow forgetting of meaning. Temporal delay has only a weak effect on the recognition of meaning-altering changes, while it has considerable effects on meaning-preserving changes.

Hypothesis 1 is specifically relevant to Hungarian. In the sentence materials, propositional, thematic structure changes were compared with changes in information structure. Propositional changes were conveyed by changes of case marking assignment in the recognition of sentences. Thus, an N1 Nominative-N2 Dative marking of Agent and Benefactor was changed in one recognition condition to N1 Dative-N2 Nominative, marking Benefactor and Agent, respectively. At the same time, changes in information structure were constructed with leaving the thematic roles and case assignment identical, but the marked constituent - in this case, the Dative - was moved to the immediately preverbal Focus position.

Hypotheses 2 to 4 are in line with the classical observations of Sachs (1967), as well as those of Johnson-Laird-Stevenson (1970). Paraphrases in this experiment were Agent-Benefactor frame changing verbs (buy and sell type) that in Hungarian also require changes in case assignment. Thus, the treatment of these paraphrases has implications about retaining the underlying role of the participants, and ignoring the exact surface marking.

\section{Methods}

In both experiments, a group study was used where subjects had to listen to tape recorded sentences, indicating at initially unforeseen points whether they have heard the given sentence before. Materials were constructed to allow testing Hypotheses 1 to 4.

Experiment I was basically a pilot study checking whether the method worked and brought along the results expected on the basis of the literature. 
Therefore, no attempt was made to balance the group size and stimulus structure of the two experiments.

\subsection{Materials}

\subsubsection{Sentence lists}

Counterbalanced lists of sentences were constructed that varied modifications of the same target sentence as shown below in (5) to (10), together with dummy controls, where no possible antecedent of the sentence was heard before.

(Supposedly) meaning-changing alterations are indicated in bold, while supposedly meaning-preserving alterations are given in italics.

(5) A lusta házaló eladta a porszívót az anyókának. ORIGINAL the lazy hawker sold the vacuum-cleaner-acc the granny-dat 'The lazy hawker sold the vacuum cleaner to the granny.'

(6) A lusta házaló eladta a porszívót az anyókának.

IDENTICAL

(7) Eladta a lusta házaló a porszívót az anyókának. sold the lazy hawker the vacuum-cleaner-acc the granny-dat

(8) Az anyóka megvette a porszivót a házalótól. 'The granny bought the vacuum cleaner from the hawker.'

(9) Az anyóka eladta a porszívót a lusta házalónak.

AGENT CHANGE 'The granny sold the vacuum cleaner to the lazy hawker.'

(10) A lusta házaló az "anyókának adta el a porszívót.

FOCUS 'The lazy hawker sold the vacuum cleaner TO THE GRANNY.'

The experimental variations - as pointed out by Ágnes Lukács in personal communication - did not exhaust all the possible sentential variations. First, there are several possible "neutral order" changes in Hungarian (cf. É. Kiss 1987; 2002). We only used an SVOD-VSOD alternation. Thus, results about neutral order variations should be interpreted with caution. Second, regarding the crucial factor of focusing, again only one constituent, the Dative was focused in the test sentences. Also, focusing was treated as a full syntactic operation involving both movement to the 
preverbal slot, separation of the prefix and moving it to postverbal position, accompanied by contrastive emphasis, elevated sound energy. Since these realizing features of Hungarian focusing were not varied independently of each other when constructing the sentence materials, we have no data on which marking feature of focus is the most crucial behaviorally. Our data are only relevant to Focusing as a general syntactic operation. Another limitation of the sentence materials was that the crucial target sentence ('original') was always the neutral variety regarding information structure.

Each type of change and dummy control sentences appeared in a randomized list with delays of $0,2,4$ and 10 sentences after the original target sentence. The delays roughly corresponded to $0,8,16$, and 40 seconds. The alterations used and the group arrangement were slightly different in the two experiments as summarized in Table 1. In Experiment I focusing was not varied, but the dummy condition was introduced, while in Experiment II dummies were not used and focusing and therefore information structure was varied between the target and test sentences.

Table 1 shows the entire experimental arrangement.

Table 1

The sentence varieties used in the two experiments

\begin{tabular}{lcccccc}
\hline Experiment & Dummy & Identical & Order & Focus & Paraphrase & Agent change \\
\hline I & $\mathrm{x}$ & $\mathrm{x}$ & $\mathrm{x}$ & & $\mathrm{x}$ & $\mathrm{x}$ \\
$\mathrm{II}$ & & $\mathrm{x}$ & $\mathrm{x}$ & $\mathrm{x}$ & $\mathrm{x}$ & $\mathrm{x}$ \\
\hline
\end{tabular}

In Experiment I, a unified list was used, with different sentences of each type for each time delay. Thus, a list of altogether 20 sentences was used, with a different target sentence for each sentence variety and for each delay ( 5 by 4 ) condition. Due to the difference between the sentences belonging to each type with each delay, interactions between sentence types and time delays should not be overinterpreted in this study.

In Experiment II, in order to control for this possible item effect, four counterbalanced lists were used. Dummy as a variable was replaced by Focusing. Each subject listened again to 20 sentences, with 5 types of changes (Identical, Order, Paraphrase, Focus, Meaning change), and with four delay conditions $(0,2,4,10$ interposed sentences). In the four lists, the four delays of each sentence change by delay conditions were randomly 
varied. Thus, over the four groups, each change and delay combination was heard for each sentence. At the same time, each subject only heard one sentence type once. Both the time and the sentence tokens were crossed between subject variables.

\subsubsection{Tape recording}

The stimulus sentences were recorded in a male voice, while the test sentences in a female voice.

\subsubsection{Procedure}

Subjects listened to the tapes over a loudspeaker in groups of 10-30 in classroom settings. They were instructed to participate in a study of human memory. Their task was to listen carefully to the sentences, pay attention both to the meaning and to the form. They were informed that they would be tested in unforeseen moments for their memory of individual sentences.

They had been given a booklet containing 20 numbered pages. They were instructed to turn the pages each time they heard a female voice, and indicate whether they have already heard the sentence. Five seconds were allowed for the written reactions after hearing the test from the tape.

\subsection{Subjects}

Students of the University of Szeged participated in the experiments as a course requirement, in classroom settings. In Experiment I, two groups of 19 and 20, thus altogether 29 subjects participated. In Experiment II, four groups were used according to the four counterbalanced experimental lists, with slightly varying sizes $(26,20,17,14)$. Altogether 77 university students took part in Experiment II.

The scores of recognizing a given sentence as already heard were used as a dependent variable.

\section{Results}

\subsection{Experiment I}

The results of Experiment I are summarized in Figure 1.

Acta Linguistica Hungarica 58, 2011 


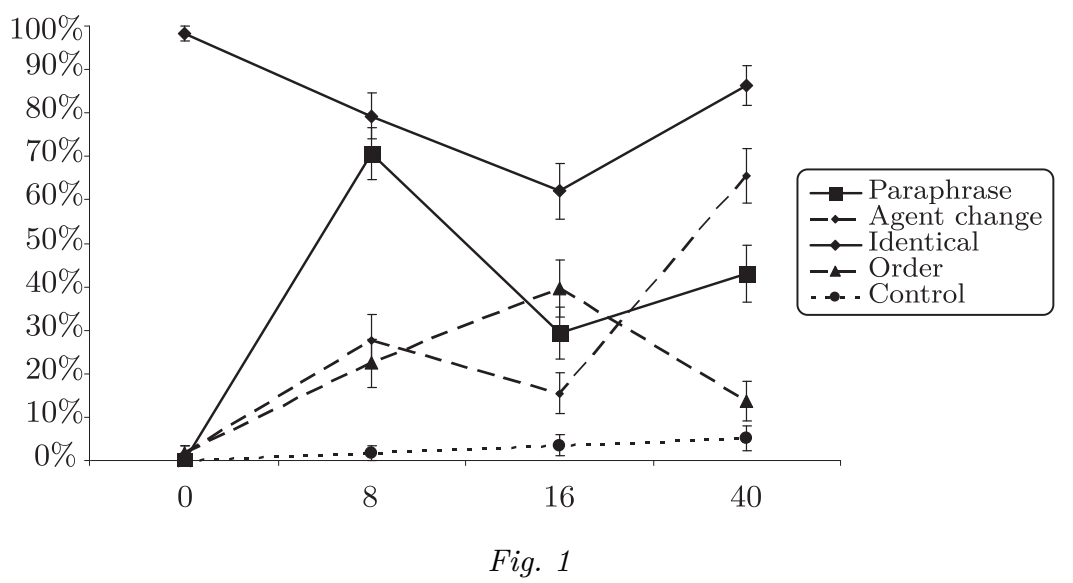

The effects of sentence changes and time in Experiment I.

Recognition of a sentence as being heard before as a function of delay time.

There was a strong main effect of time $(F(3,84)=12.46, p<0.00001)$, and a strong main effect of sentence type $(F(4,112)=81.53$, $p<0.00001)$. The interaction was also very significant $(F(12,336)=$ $27.20, p<0.00001)$.

There is hardly any response bias and false recognition of sentence never heard earlier, that is, of the dummy controls (5\%). Identical sentences are reliably recognized. Order changes, in line with Hypothesis 2, become unnoticed with the change of time, while paraphrases and agent changes are noticed.

The main effect of time is rather clear. In the no delay condition, identical sentences are differentiated from all the others with a $100 \%$ correct recognition. In all the delays there is increasing false recognition, the grand means being 23, 39, 36 and 39 percents, after $0,8,16$ and 40 seconds. The real difference is between no delay and all the delays. Post hoc tests showed a $0>[8,16,40]$ ordering with a significant difference between 8 and 40 seconds as well.

\subsection{The effects of focusing (Experiment II)}

In Experiment II, the creation of four subgroups allowed for a clear characterization of time delays as a function of test sentence changes. Both Time $(F(3,216)=17.66, p<0.0001)$ and Type $(F(4,288)=75.62, p<$ $0.00001)$ were significant. There was no interaction between the grouping variables and the two within-subject factors, which suggests that the 
effects both of time and order are worth interpreting. The interaction of Time and Sentence structure was significant $(F(12,864)=7.23, p<$ $0.00001)$

The interactions are summarized in Table 2 and Figure 2.

Table 2

Meaning-preserving (italics) and meaning-changing (bold) alterations as a function of time in Experiment II. Percentages of identifying the sentence as one heard before.

\begin{tabular}{cccccc}
\hline Secs & Ident & Order & Para & Agent & Focus \\
\hline 0 & 66 & 10 & 6 & 2 & 13 \\
8 & 72 & 35 & 25 & 26 & 21 \\
16 & 54 & 65 & 22 & 29 & 16 \\
40 & 74 & 63 & 37 & 25 & 22 \\
\hline
\end{tabular}

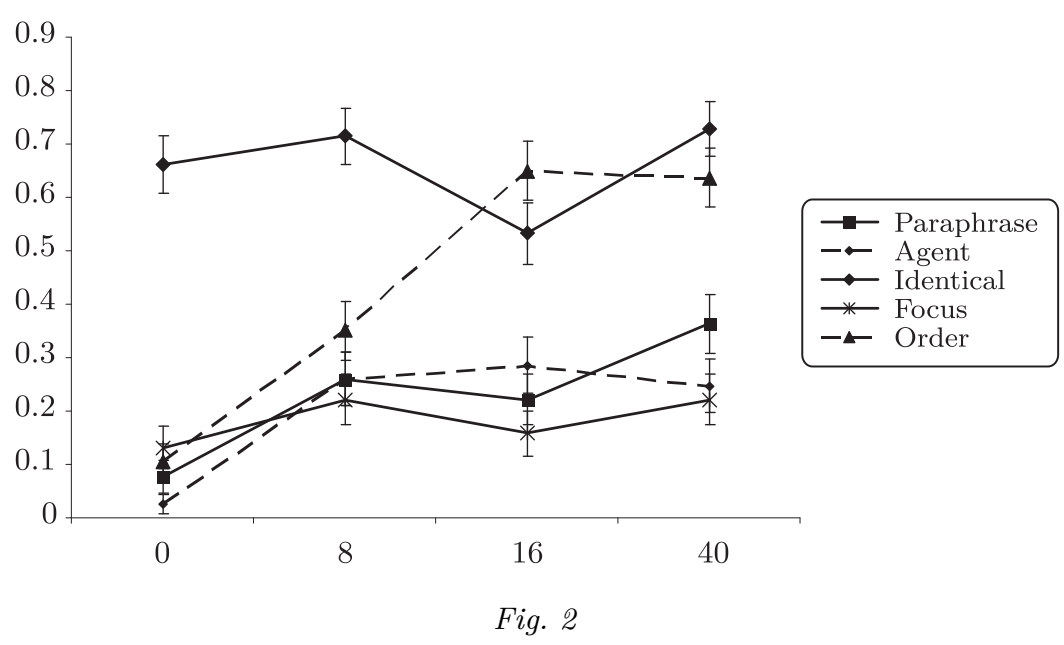

The effects of sentence changes and time in Experiment II. Recognition of a sentence as being heard before as a function of delay time.

Regarding Hypotheses 1 and 2, the most interesting result is that while neutral word order changes begin to be ignored already after two intervening sentences, the fact that the initial target sentence was neutral regarding Focusing information is preserved even after the longest times used. In post hoc comparisons, the relative ordering of the delay in neutral conditions was $0>8>(16,40)$, while in pairwise comparisons, interestingly enough, there is no effect of time on the recognition of contrastively focused sentences. Thus, focused sentences are clearly contrasted with 
the initial neutral sentence. Figure 3 summarizes this in terms of correct recall.

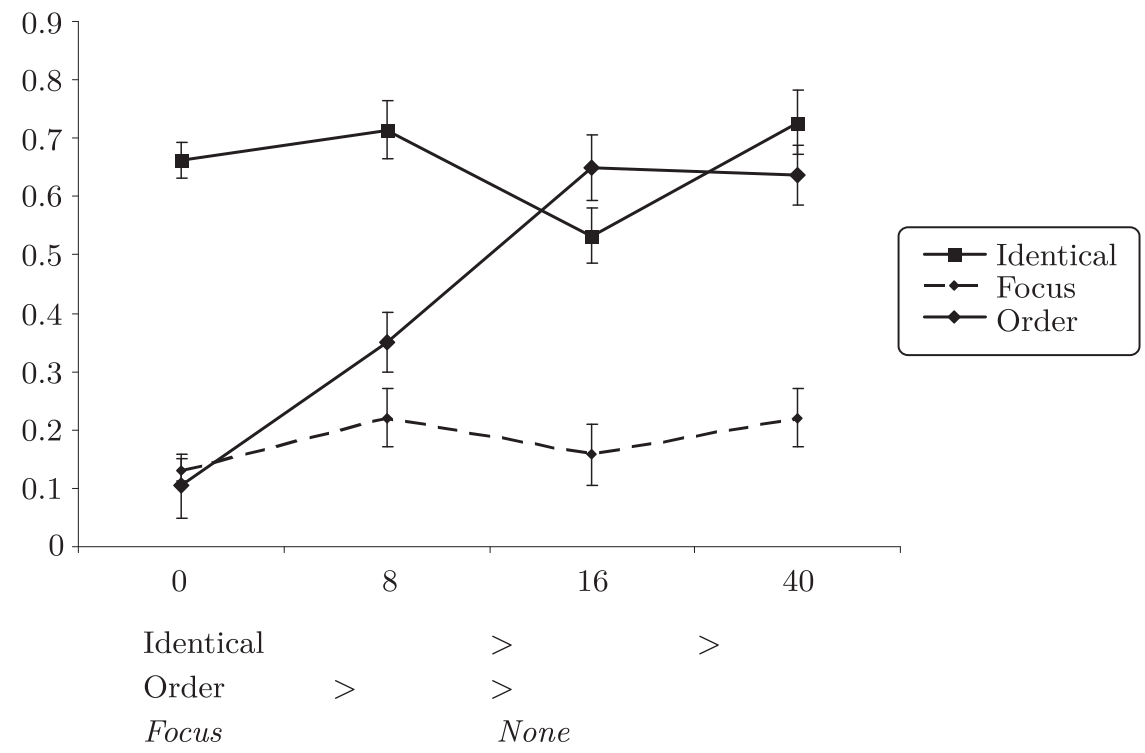

Fig. 3

A comparison of sentence recognition correctness as a function of time in neutral and focusing word order variations compared to the baseline (identical); > indicates contrasts that are significant.

These data thus do support both Hypotheses 1 and 2. As for Hypothesis 3, as Figure 4 shows, subjects maintained the differences between paraphrases and the original sentence except in the longest delay condition. The effect of sentence types was strongly significant $(F(1,76)=$ $132.58, p<0.0001)$. The effect of time was also significant $(F(3,74)=$ $6.039, p<0.001)$. The interaction was significant $(F(3,74)=2.85, p<$ $0.05)$ and was mainly due to a general increase of acceptance after the longest delays. For identical sentences there was no effect of time. For paraphrases, however, a $0>(8,16)>40$ significant order was obtained in post hoc contrasts. Thus, these data seem to question Hypothesis 3: at least in the types of role-reversing paraphrases we used, and with the delays used here, differences between selling and buying are maintained even after 40 seconds.

As for Hypothesis 4, Figure 5 summarizes the differences between the correct recognition of paraphrases and agent changes. The recognition of 


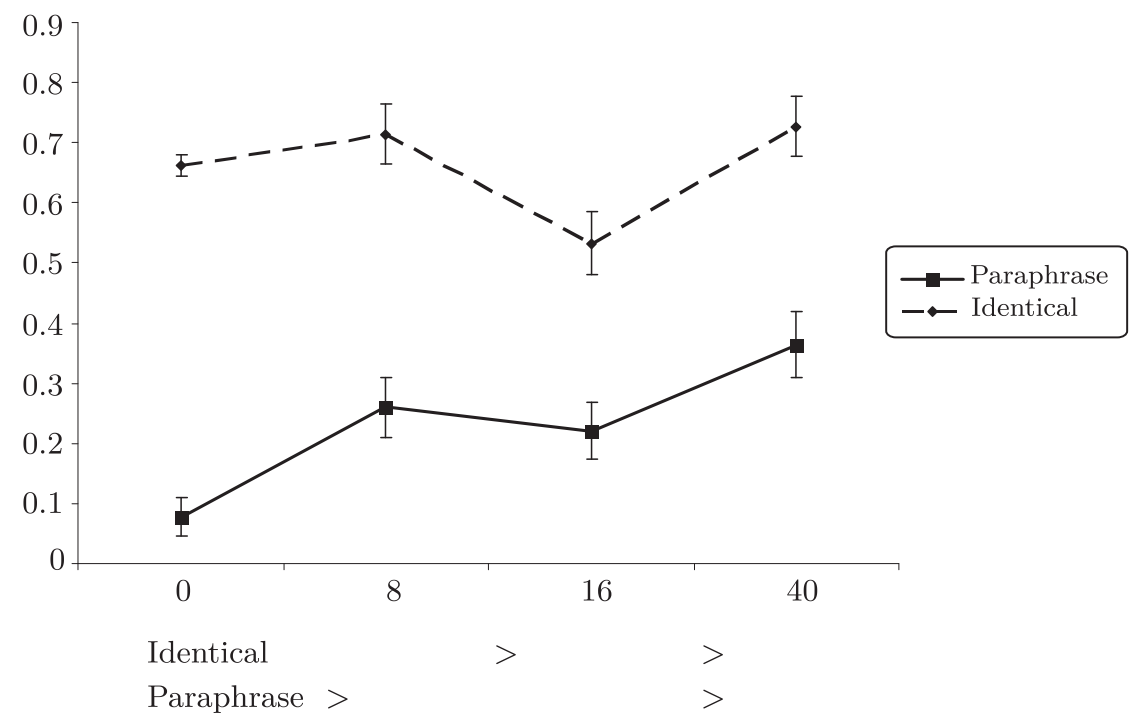

Fig. 4

Paraphrases are not treated as equivalent to the original sentence after short delays

the alterations diverges after 40 seconds, but not earlier. At the same time, both agent-changing sentences and paraphrases are less clearly represented after the shortest delay (compared to no delay). Paraphrases for a long time are not misrecognized as being identical to the original. Thus Hypothesis 4 is only supported for relatively long delay, not unlike the time delays used by Johnson-Laird and Stevenson (1970).

\section{Discussion}

The two experiments on acoustic sentence recognition in Hungarian were performed with the aim of further clarifying the general idea that "syntax goes away easily, while meaning is retained" in a language that allows for elaborate case frame changes in sentential paraphrases and for meaningrelevant changes of word order.

The results partly supported our starting hypotheses, but partly showed that the intricacies of Hungarian sentential syntax call for a more reserved and more carefully qualified expression of the initial proposals of Sachs (1967) and Johnson-Laird-Stevenson (1970). 


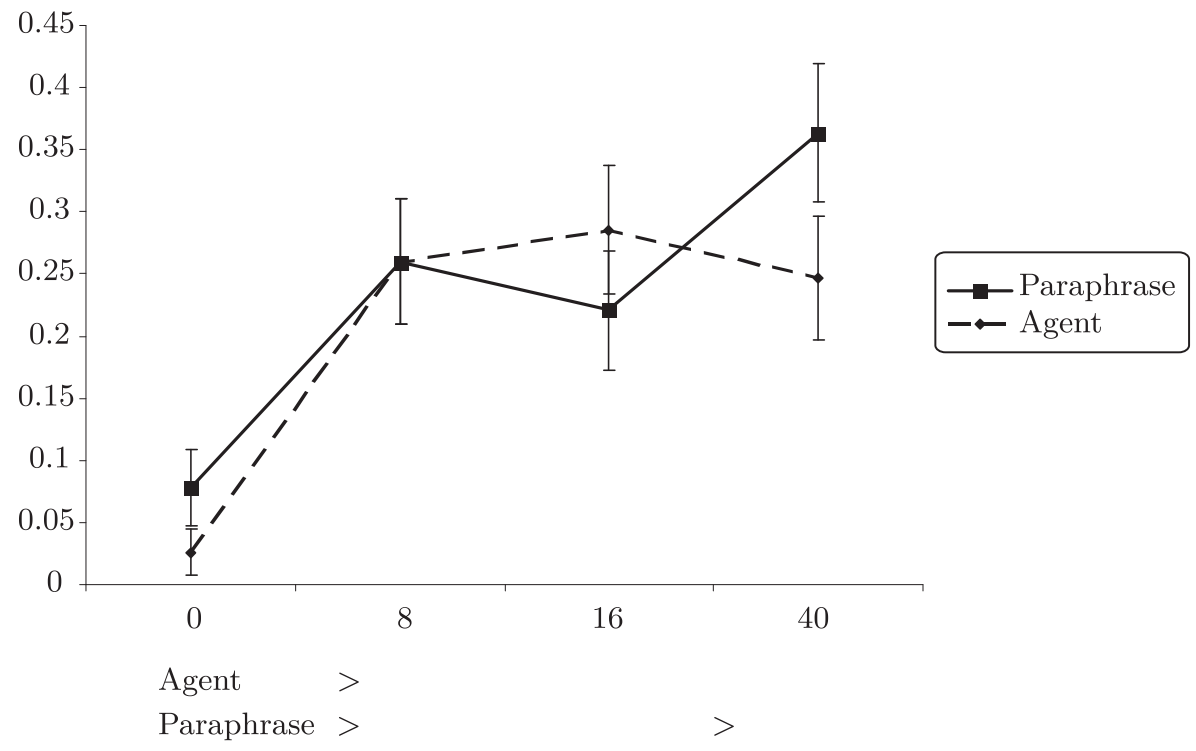

Fig. 5

The correct recognition of agent changes and periphrastic changes only diverges after 40 seconds

Hypothesis 1 (Meaning-relevant word order changes are retained) is corroborated by our data in Experiment II. Focused sentences are clearly contrasted with non-focused initial targets even after 40 seconds. It seems to be the case that the information structure is somehow maintained in the long-term memory system for sentences in Hungarian. This finding opens new challenges. First, one would like to see with a careful manipulation of the stimulus features of focusing which ones are crucial here, order, prefix movement, or stress pattern. Also, our experiments had a clear limitation related to the construction of sentence materials. The starting sentence against which the test sentences were tested was always neutral in its informational structure. It would be important to see what happens when the target sentence is contrastive. Using this more sophisticated material would allow us to test the claim whether focusing facilitates specific maintenance of the focused sentence.

Hypothesis 2 (Forgetting of form) was supported with neutral word order variations in both experiments. In accordance with the classical results, meaning-neutral word order variations are misrecognized in about 60 per cent after 16 seconds already. 
With respect to Hypothesis 3 (Meaning equivalence of paraphrases in memory), our results were not as clear-cut. Even after 40 seconds, paraphrases are correctly recognized more than 60 per cent of the time. This again raises a serious stimulus issue. Our results might be due to the fact that in Hungarian the SELL-BUY types of changes involved changes not only in the thematic structure, but in the morphology as well. Thus, to clarify to cross-linguistic validity of memorial paraphrase equivalence more types of sentential paraphrases should be compared.

Hypothesis 4 (Fast forgetting of form, slow forgetting of meaning) should also be treated with reservations. It seems that due to the peculiar behavior of the paraphrases in our study some variations that were intended to be formal were treated as meaning-related by the system, and were maintained even for 40 seconds.

Thus, in short, the studies supported the main ideas underlying the experiments: the informational structure of the Hungarian sentence seems to be retained in long-term memory, unlike neutral word order variations. This finding calls for a more detailed study with more varied stimulus materials to clarify some further issues of what is "form" and what is "meaning" for the memory system.

\section{References}

Anderson, John R.-Raluca Budiu-Lynne M. Reder 2001. A theory of sentence memory as part of a general theory of memory. In: Journal of Memory and Language $45: 337-67$.

Clark, Eve V.-Herbert H. Clark 1977. Psychology and language: An introduction to psycholinguistics. Harcourt Brace Jovanovich, New York.

É. Kiss, Katalin 1981a. Syntactic relations in Hungarian, a "free" word order language. In: Linguistic Inquiry $12: 185-215$.

É. Kiss, Katalin 1981b. Topic and focus: The operators of the Hungarian sentence. In: Folia Linguistica (Acta Societatis Linguistica Eurpaeae) 16:305-30.

É. Kiss, Katalin 1987. Configurationality in Hungarian. Reidel/Akadémiai Kiadó, Dordrecht/Budapest.

É. Kiss, Katalin 2002. The syntax of Hungarian. Cambridge University Press, Cambridge.

Fillenbaum, Samuel 1973. Syntactic factors in memory? Mouton, The Hague.

Flores d'Arcais, Giovanni B. 1974. Is there a memory for sentences? In: Acta Psychologica $38: 33-58$.

Johnson-Laird, Philip N.-Rosemary Stevenson 1970. Memory for syntax. In: Nature $227: 412$.

Acta Linguistica Hungarica 58, 2011 
Kiefer, Ferenc 2005. On the information structure of the Hungarian sentence. In: Hungarian Studies 19:255-65.

Kintsch, Walter 1974. The representation of meaning in memory. Erlbaum, Mahlah, NJ.

Kintsch, Walter-David Welsch-Franz Schmalhofer-Susan Zimny 1990. Sentence memory: A theoretical analysis. In: Journal of Memory and Language 29 : 133-59.

Lambrecht, Knud 1994. Information structure and sentence form. A theory of topic, focus, and the mental representations of discourse referents. Cambridge University Press, Cambridge.

Pléh, Csaba-Farrel Ackermann-András Komlósi 1989. On the psycholinguistics of preverbal modifiers in Hungarian: Adult intuitions and children's treatment of modifiers. In: Folia Linguistica (Acta Societatis Linguistica Eurpaeae) 23:181214.

Sachs, Jacqueline Strunk 1967. Recognition memory for syntactic and semantic aspects of connected discourse. In: Perception and Psychophysics $2: 437-42$. 